\title{
Avaliação em obra da resistência superficial de revestimentos de argamassa
}

\author{
H. Carasek ${ }^{1}$, O. Cascudo ${ }^{1}$, M. S. J. dos $\operatorname{Santos}^{1}$, N. Lemes ${ }^{1}$ \\ ${ }^{1}$ Universidade Federal de Goiás, Escola de Engenharia Civil, Praça Universitária, s/n., CEP 74605-220, Goiânia - GO - Brasil.
}

\begin{abstract}
Información del artículo
DOI:

http://dx.doi.org/10.21041/ra.v

$\underline{1 i 2.10}$

Artículo recibido el 19 de

Octubre de 2010, revisado

bajo las políticas de publicación de la Revista ALCONPAT y aceptado el 05 de Enero de 2011. Cualquier discusión, incluyendo la réplica de los autores se publicará en el primer número del año 2012 siempre y cuando la información se reciba antes del cierre del tercer número del año 2011
\end{abstract}

\section{(C) 2011 Alconpat Internacional}

\section{Información Legal}

Revista ALCONPAT, Año 1, No. 2, Mayo Agosto 2011, es una publicación cuatrimestral de la Asociación Latinoamericana de Control de Calidad, Patología y Recuperación de la Construcción, Internacional, A.C., Km. 6, antigua carretera a Progreso, Mér

C.P. 97310, Tel.5219997385893,
alconpat.int@ @mail.com, Página Web: alconpat.int@gmail.c

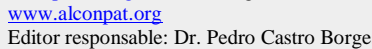
Reserva de derechos al uso exclusivo No.04 2013-011717330300-203, eISSN 2007-6835, ambos otorgados por el Instituto Nacional de Derecho de Autor. Responsable de la última actualización de este número, Unidad de Informática ALCONPAT, Ing. Elizabeth Sabido Maldonado, Km. 6, antigua carretera a Progreso, Mérida Yucatán, C.P. 97310, fecha de publicación: 30 de mayo de 2011.

Las opiniones expresadas por los autores no necesariamente reflejan la postura del editor. Queda totalmente prohibida la reproducción total o parcial de los contenidos e imágenes de la publicación sin previa autorización de la ALCONPAT Internacional A.C.

\section{RESUMO}

O presente trabalho tem como objetivo avaliar, em obra, a resistência superficial à tração (RST) de revestimentos de argamassa. O ensaio para avaliação dessa propriedade ainda não é normalizado no Brasil, merecendo, portanto, estudos visando a sua futura padronização, haja vista ser a resistência superficial de um revestimento de argamassa um dos aspectos relevantes no que tange ao seu desempenho. Neste sentido, foram realizadas avaliações em duas obras de diferentes construtoras na cidade de Goiânia (estado de Goiás, Brasil), onde foram analisadas a influência do operador do ensaio, as influências do traço, local de aplicação e idade do revestimento, e a influência da ergonomia durante a produção do revestimento. Os resultados obtidos foram analisados empregando procedimentos estatísticos, tendo sido calculado o tamanho da amostra e realizadas análises de variâncias, além de correlações entre a RST e outros ensaios realizados. Como resultado, obteve-se que o tamanho da amostra compatível com a variabilidade obtida no ensaio é de 10 a 15 corpos-deprova por situação individual de análise. Também se verificou que as variáveis estudadas (traço da argamassa, idade do revestimento e ação de intempéries) exercem influência significativa nos resultados de RST. Foram observadas correlações satisfatórias entre a RST e os resultados de ensaios de resistência de aderência $(r=0,87)$, permeabilidade $(r=0,81)$ e índice esclerométrico $(\mathrm{r}=0,99)$.

Palavras chave: revestimento; argamassa; resistência superficial; ensaio in situ.

\section{ABSTRACT}

This study aims to evaluate the surface tensile strength (STS) of mortar renderings on site. The test for evaluating this property is not yet standardized in Brazil, therefore, it deserves studies towards its standardization, considering that it is one of the most relevant properties concerning the performance of renderings. The evaluations were conducted in two different construction sites in the city of Goiânia (Goiás, Brazil), which analyzed the influence of the operator of the test, the mortar mix proportions, age and site of rendering application, as well as the influence of ergonomics factors during render production. The results were analyzed using statistical procedures, estimating the sample size and performing an analysis of variance, as well correlations between the STS and other tests. It was found that the sample size compatible with the variability obtained in the test was 10 to 15 samples per individual condition of analysis. It was also noted that the factors (mix proportion of mortar, age of the rendering and bad weather action) exert significant influence on the results of STS. Satisfactory correlations between the STS and the results of bond strength $(r=0.87)$, water permeability $(\mathrm{r}=0.81)$ and sclerometric index $(\mathrm{r}=0.99)$.

Key words: render; mortar; surface tensile strength; in situ test.

Autor de contacto: Helena Carasek (hcarasek@ gmail.com) 
Revista ALCONPAT, Volumen 1, Número 2, Mayo - Agosto 2011, Páginas 115 - 135

\section{INTRODUÇÃO}

O emprego de revestimentos de argamassa no Brasil é uma das práticas mais comuns em obras de edifícios multipavimentos, sendo utilizados para receber o acabamento em pintura, ou como emboço na aplicação do acabamento de peças cerâmicas.

Para avaliar o desempenho do revestimento de argamassa é necessário que sejam feitas inspeções através de ensaios e procedimentos de verificação relativos à qualidade, constatando seu potencial, sobretudo em relação à durabilidade.

As principais funções de um revestimento de argamassa de parede são:

a) proteger a alvenaria e a estrutura contra a ação do intemperismo, no caso dos revestimentos externos;

b) integrar o sistema de vedação dos edifícios, contribuindo com diversas funções, tais como: isolamento térmico ( 30\%), isolamento acústico ( 50\%), estanqueidade à água ( 70 a 100\%), segurança ao fogo e resistência ao desgaste e abalos superficiais;

c) regularizar a superfície dos elementos de vedação e servir como base para acabamentos decorativos, contribuindo para a estética da edificação.

Visando satisfazer às funções citadas anteriormente, algumas propriedades tornam-se essenciais para essas argamassas, a saber:

a) trabalhabilidade, especialmente consistência, plasticidade e adesão inicial;

b) retração;

c) aderência;

d) permeabilidade à água;

e) resistência mecânica, principalmente a superficial;

f) capacidade de absorver deformações.

No caso específico da resistência mecânica, propriedade discutida neste trabalho, ela diz respeito à propriedade dos revestimentos de possuírem um estado de consolidação interna capaz de suportar esforços mecânicos das mais diversas origens e que se traduzem, em geral, por tensões simultâneas de tração, compressão e cisalhamento. Esforços como o desgaste superficial, impactos ou movimentação higroscópica são exemplos de solicitações que exigem resistência mecânica dos revestimentos, pois geram tensões internas que tendem a desagregá-los (Selmo, 1989). Um dos principais problemas nos revestimentos, associado à resistência mecânica da argamassa, é a baixa resistência superficial, que se traduz na pulverulência, prejudicando a fixação das camadas de acabamento, como a pintura ou, mais grave ainda, as peças cerâmicas (Carasek, 2007).

A análise e o diagnóstico da resistência superficial dos revestimentos de argamassa têm utilizado diferentes parâmetros indiretos que buscam medir principalmente a resistência ao desgaste superficial ou à abrasão, à pulverulência, ao impacto e ao risco, conforme citado no documento do National Center for Preservation Technology and Training (1999).

Tendo em vista a necessidade de se obter parâmetros e valores práticos que avaliam o revestimento de uma forma direta, no Brasil tem sido utilizado em obras e em pesquisas no meio científico1 o ensaio de resistência superficial à tração - RST, adaptado do método de ensaio de determinação da resistência de aderência à tração da NBR 13.528 (ABNT, 1995), ainda não normalizado, considerando esta característica superficial do revestimento. Cabe destacar-se que o método brasileiro de determinação da resistência de aderência é similar ao prescrito pela norma européia EN 1015-12 (2000).

\footnotetext{
${ }^{1}$ Alguns trabalhos brasileiros que citam o emprego deste método adaptado são: Pereira (2000); Pereira, Francinete Jr. e Carasek (2005) Temoche-Esquivel et al. (2005); Costa (2007).

H. Carasek, O. Cascudo, M. S. J. dos Santos, N. Lemes
} 
Revista ALCONPAT, Volumen 1, Número 2, Mayo - Agosto 2011, Páginas 115 - 135

\section{OBJETIVO}

Constitui-se objetivo deste trabalho estudar diversos aspectos relacionados ao método de ensaio de determinação da resistência superficial por tração, adaptado do método prescrito pela ABNT: NBR 13528 para avaliação da resistência de aderência à tração. Os aspectos avaliados foram: influência do operador, variabilidade dos resultados e determinação do tamanho da amostra, influência do proporcionamento da argamassa e da idade do revestimento, influência da ergonomia, além de correlações entre resistência superficial e outros ensaios realizados no revestimento.

\section{METODOLOGIA}

Foi realizado um estudo experimental, em duas obras de edifícios multipavimentos da cidade de Goiânia, Goiás, Brasil (denominadas neste trabalho Obra A e B), de duas diferentes construtoras, sendo separados em cada uma delas dois painéis de alvenaria de blocos cerâmicos que foram revestidos com argamassa e testados quanto à resistência superficial.

\subsection{Materiais}

Os materiais empregados no preparo das argamassas de chapisco e de revestimento foram os seguintes:

a) Obra A: cimento Portland CP II-Z, cal hidratada $\mathrm{CH}-\mathrm{III}$ e areia natural de rio média;

b) Obra B: cimento Portland CP II-Z, cal hidratada CH-I e areia natural de rio média.

O chapisco foi preparado com um proporcionamento de 1:3, em volume, cimento e areia, para as duas obras. Já a argamassa de revestimento foi preparada com distintos traços em volume, a saber: 1:1:6 e 1:2:8, respectivamente para as obras A e B.

As Tabelas 1 e 2 apresentam um resumo da caracterização das argamassas empregadas, no estado fresco e no estado endurecido, respectivamente.

Tabela 1. Caracterização das argamassas no estado fresco.

\begin{tabular}{|c|c|c|c|}
\hline \multirow{2}{*}{ ENSAIO } & \multirow{2}{*}{ NORMA } & \multicolumn{2}{|c|}{ RESULTADO MÉDIO } \\
\cline { 3 - 4 } & Obra A & Obra B \\
\hline $\begin{array}{c}\text { Densidade de massa } \\
\left(\mathrm{g} / \mathrm{cm}^{3}\right)\end{array}$ & NBR 13278 (1995) & 1,96 & 1,86 \\
\hline $\begin{array}{c}\text { Penetração do cone } \\
(\mathrm{mm})\end{array}$ & ASTM C 780 (1996) & 43,75 & 56,88 \\
\hline Retenção de água (\%) & NBR 13277 (1995) & 90,23 & 91,12 \\
\hline $\begin{array}{c}\text { Teor de ar incorporado } \\
(\%)\end{array}$ & NBR 11686 (1990) & 2,53 & 7,50 \\
\hline
\end{tabular}

Tabela 2. Caracterização das argamassas no estado endurecido. 
Revista ALCONPAT, Volumen 1, Número 2, Mayo - Agosto 2011, Páginas 115 - 135

\begin{tabular}{|r|c|c|c|c|c|}
\hline \multirow{2}{*}{ ENSAIO } & \multirow{2}{*}{ NORMA } & \multicolumn{3}{|c|}{ RESULTADO MÉDIO } \\
\cline { 3 - 6 } & & \multicolumn{2}{|c|}{ OBRA A } & \multicolumn{2}{c|}{ OBRA B } \\
\cline { 3 - 6 } & & $\mathbf{7}$ dias & $\mathbf{3 5}$ dias & $\mathbf{7}$ dias & $\mathbf{3 5}$ dias \\
\hline $\begin{array}{r}\text { Resistência à } \\
\text { compressão (MPa) }\end{array}$ & NBR 5739 (1986) & 4,07 & 7,24 & 2,88 & 3,86 \\
\hline $\begin{array}{r}\text { Resistência à } \\
\text { tração (MPa) }\end{array}$ & NBR 7222 (1982) & 0,59 & 0,89 & 0,37 & 0,50 \\
\hline
\end{tabular}

\subsection{Métodos de ensaio}

O ensaio de determinação da resistência superficial por tração (RST) realizado não é ainda normalizado e baseia-se no método de determinação da resistência de aderência à tração - NBR 13528 (ABNT, 1995), sendo a única diferença que não é realizado o corte do revestimento (até a base), ensaiando-se assim a camada superficial do revestimento.

Assim, para a realização do ensaio RST foi utilizado um equipamento para a aplicação de esforço à tração (equipamento hidráulico-manual com capacidade de carga de $1 \mathrm{kN}$ e acurácia $2 \%$, do fabricante Consultare), pastilhas metálicas circulares com $50 \mathrm{~mm}$ de diâmetro e cola de base poliéster. A realização do ensaio seguiu as seguintes etapas:

a) Limpeza da superfície e execução da marcação com gabarito das posições onde seria realizado o ensaio;

b) Colagem da pastilha (Figuras 1 e 2);

c) Após a secagem da cola, acoplamento do equipamento de aplicação de esforço à tração na pastilha (Figura 3);

d) Aplicação da carga até a ruptura da fração superficial do revestimento (Figura 4);

e) Anotação da carga e registro da forma de ruptura (diâmetro e profundidade do arrancamento) observado nas Figuras 5 e 6.

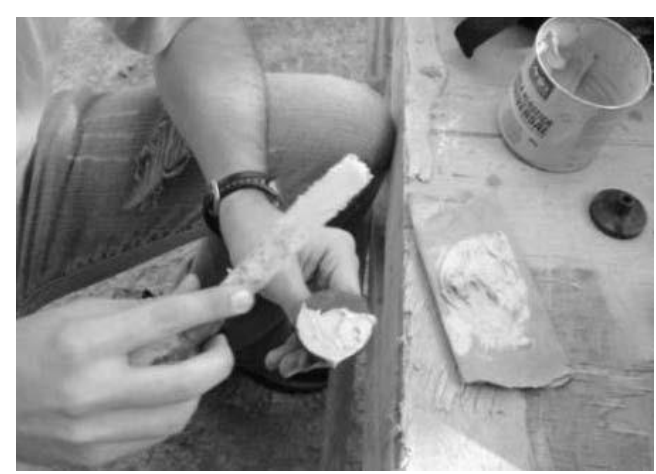

Figura 1. Aplicação da cola na pastilha para posteriormente fixar na parede

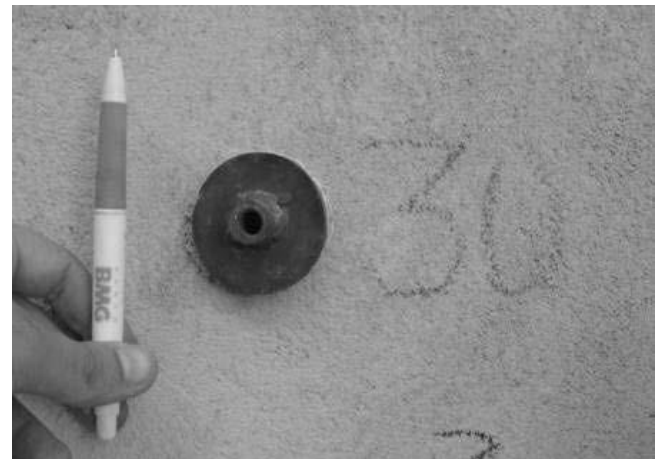

Figura 2. Pastilha metálica colada no revestimento. 
Revista ALCONPAT, Volumen 1, Número 2, Mayo - Agosto 2011, Páginas 115 - 135

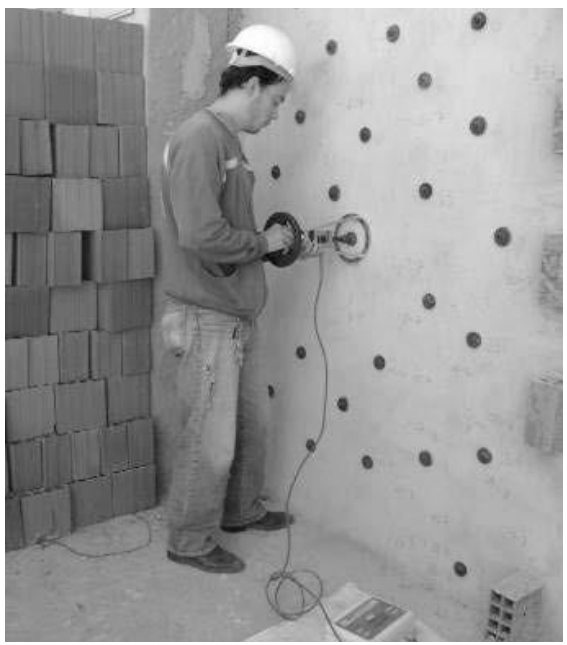

Figura 3. Realização do ensaio

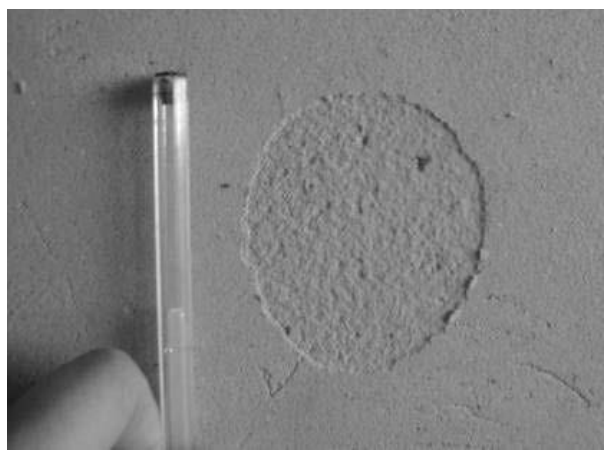

Figura 5. Ruptura tipo superficial

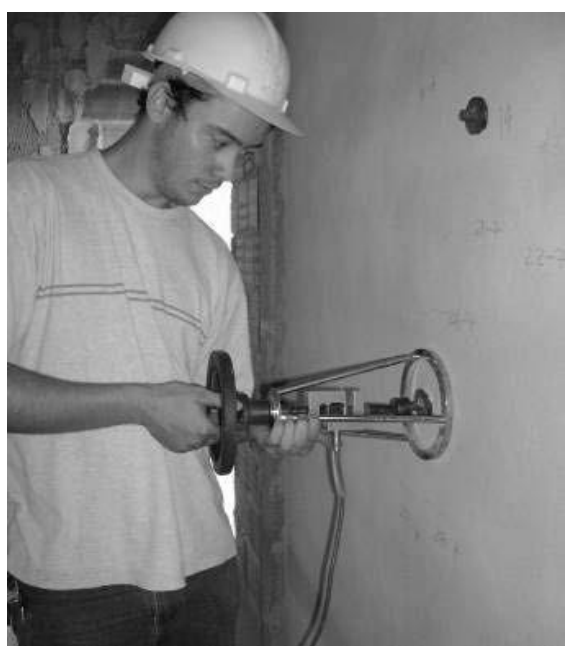

Figura 4. Detalhe da célula de carga do equipamento de arranchamento

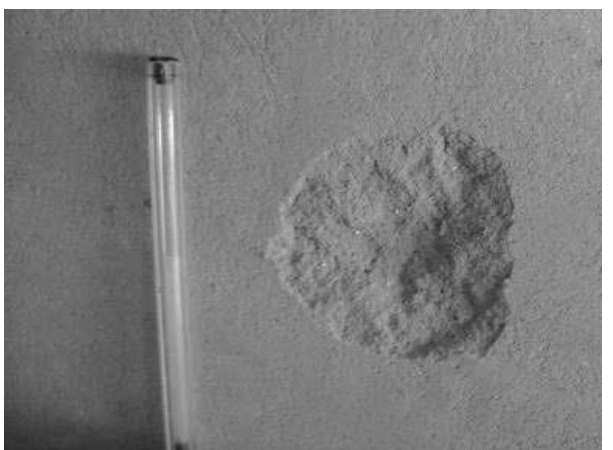

Figura 6. Ruptura tipo profunda

Em cada painel testado foram ensaiados 30 corpos-de-prova de RST, sendo realizados ensaios nas idades de 7 e 35 dias após a execução do revestimento. Apenas em uma das situações não foi realizado o teste aos 35 dias, e em alguns casos foram perdidos alguns poucos resultados (problemas de ensaio) resultando, portanto, um total de 202 corpos-de-prova testados e válidos para análise.

Complementarmente, foram realizados os ensaios de resistência de aderência à tração - NBR 13528 (ABNT, 1995), com 6 corpos-de-prova, permeabilidade/absorção de água pelo método do cachimbo CSTC - NIT 140 (CSTC, 1982), com 3 corpos-de-prova (Figura 7), e esclerometria de pêndulo, com 10 impactos por situação (Figura 8). 


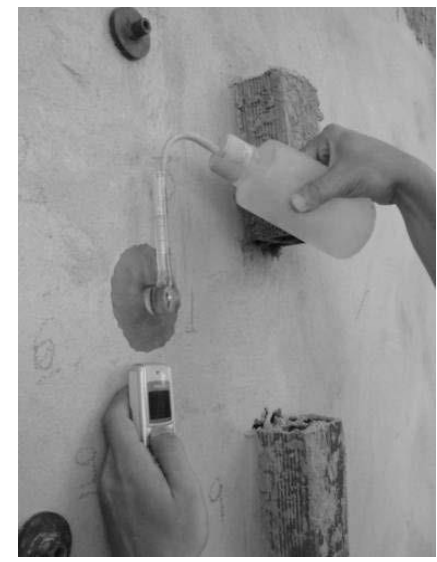

Figura 7. Ensaio de Permeabilidade/absorção.

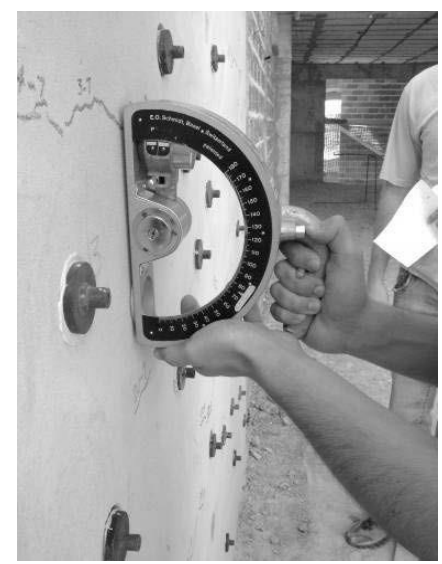

Figura 8. Esclerômetro de pêndulo.

\subsection{Condições dos painéis testados}

Em cada obra, os painéis de alvenaria de blocos cerâmicos, com dimensões de aproximadamente 2,5 m x 2,5 m, foram revestidos seguindo o procedimento adotado por cada uma das empresas. Em cada obra, testou-se um painel com preparo da base (chapisco) e um sem preparo.

Todos os painéis de revestimento em argamassa foram executados por profissionais experientes que realizaram as etapas de chapisco (nas paredes pré-definidas), lançamento da argamassa (Figura 9), sarrafeamento com régua metálica e acabamento com desempenadeira (Figura 10). Cabe destacarse que estes procedimentos sofrem variações da força do lançamento (na aplicação) e da pressão exercida no sarrafeamento e desempeno (acabamento) em função da ergonomia do operador (observar nas Figuras 9 e 10 que na altura média do painel as condições de trabalho são bem melhores do que na parte superior ou inferior).

No caso da realização dos ensaios, cuidados especiais foram tomados para garantir posição ergonônica do operador, utilizando-se para tanto uma plataforma quando da realização dos ensaios nas partes superiores dos painéis (Figura 11). Os experimentos foram realizados por três operadores distintos $(\alpha, \beta$ e $\gamma)$, mas a grande maioria por dois deles por $\alpha$ e $\beta$, que, portanto, serão objeto de análise neste artigo.

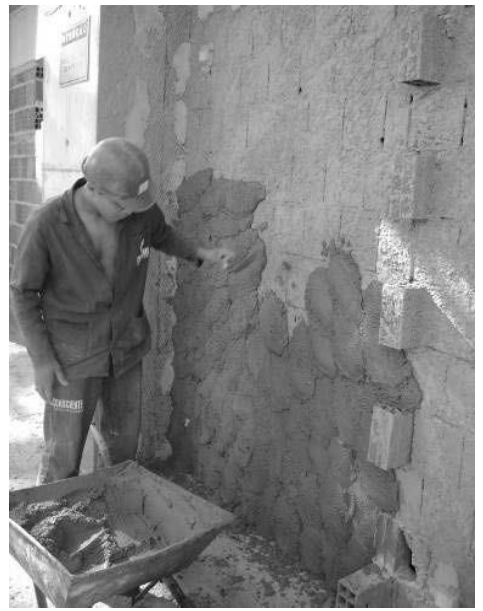

Figura 9. Aplicação manual da argamassa na parede.

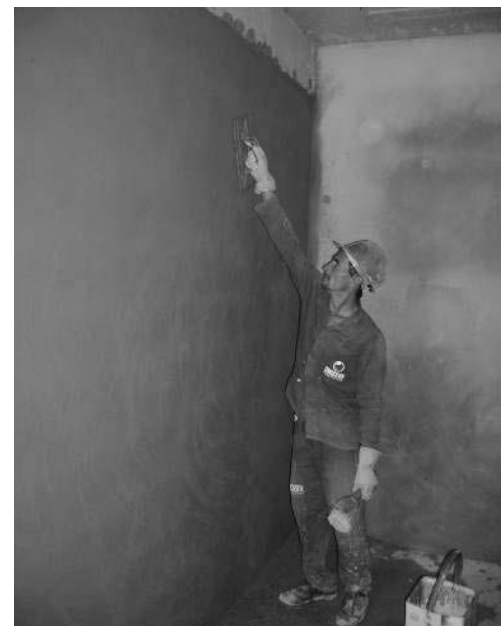

Figura 10. Desempenamento do emboço para o acabamento. 


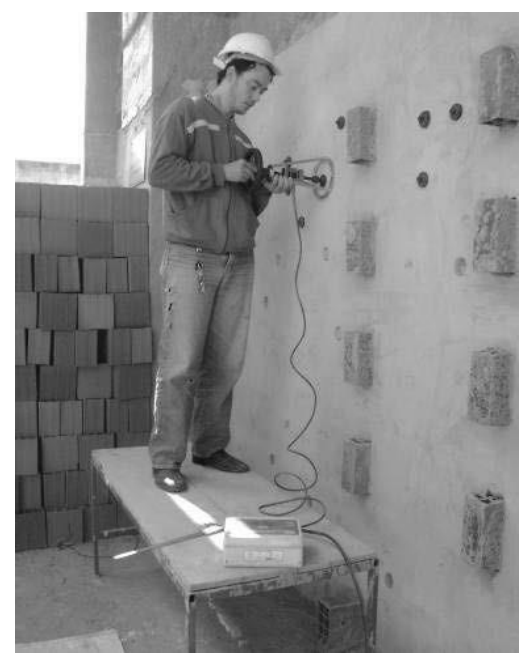

Figura 11. Realização do ensaio em alturas mais elevadas.

A Tabela 3 apresenta um resumo das condições de cada um dos painéis testados.

Tabela 3. Condição dos painéis testados.

\begin{tabular}{|c|c|c|c|c|c|c|}
\hline OBRA & $\begin{array}{c}\text { CÓDIGO } \\
\text { DO } \\
\text { PAINEL }\end{array}$ & LOCAL & CHAPISCO & $\begin{array}{l}\text { OPERADOR } \\
\text { DO ENSAIO }\end{array}$ & $\begin{array}{c}\text { IDADE } \\
\text { TESTADA }\end{array}$ & $\begin{array}{c}\text { NÚMERO DE } \\
\text { CP'S } \\
\text { TESTADOS }\end{array}$ \\
\hline \multirow{4}{*}{ A } & A1 & Interno & $\operatorname{sim}$ & $\alpha+\gamma$ & 7 dias & 27 \\
\hline & A2 & Interno & Sim & $\alpha$ & 35 dias & 30 \\
\hline & A3 & Externo & Não & $\alpha+\beta$ & 7 dias & 28 \\
\hline & A4 & Externo & não & $\beta$ & 35 dias & 30 \\
\hline \multirow{3}{*}{ B } & B1 & Interno & Não & $\alpha$ & 7 dias & 29 \\
\hline & B2 & Externo & Sim & $\alpha$ & 7 dias & 29 \\
\hline & B3 & Externo & $\operatorname{sim}$ & $\beta+\alpha$ & 35 dias & 29 \\
\hline \multicolumn{6}{|c|}{ Total de corpos-de-prova } & 200 \\
\hline
\end{tabular}

\subsection{Avaliações realizadas}

Com os resultados obtidos no ensaio de resistência superficial para cada painel, calcularam-se os valores médios e os coeficientes de variação. Foi então realizada uma análise cronológica da evolução dos coeficientes de variação obtidos nos painéis testados, visando verificar se ocorria a redução do coeficiente de variação à medida que os diferentes operadores do ensaio adquiriam prática na sua realização.

Após isto, com base em um coeficiente de variação médio, foi realizada uma análise estatística, baseada em Nanni e Ribeiro (1987), visando determinar o tamanho da amostra ideal para o ensaio, empregando o coeficiente de variação médio obtido nos ensaios em obra. Para tanto, adotou-se o seguinte procedimento:

Para a obtenção do número de amostra (n) utilizou-se a fórmula:

$$
n=Z_{\alpha / 2}^{2} * \frac{C V^{2}}{E R^{2}}
$$

Onde: $\mathrm{CV}=$ Coeficiente de variação; $\mathrm{ER}=$ Erro relativo; $\mathrm{Z} \alpha / 2=$ Variável padronizada da função de distribuição normal. 
Posteriormente ajustou-se sucessivamente o valor de " $n$ " encontrado através da tabela " $t$ de Student", determinando o valor de "n" final através da fórmula:

$$
n=t_{\alpha / 2}^{2} * \frac{C V^{2}}{E R^{2}}
$$

Quando "n” final dos sucessíveis ajustes tornaram-se iguais, assumiu-se que o ajuste converteu para o tamanho da amostra.

Outra avaliação realizada foi quanto à influência da ergonomia nos resultados de resistência superficial, ou seja, a influência da posição do revestimento testado no painel (principalmente a altura) em relação às condições de aplicação da argamassa pelo pedreiro. Assim, os 30 corpos-deprova em cada painel, foram distribuídos aleatoriamente em toda a área e identificados com relação a sua posição por meio de coordenadas (XY).

Também com os resultados dos ensaios de Resistência Superficial à Tração (RST), realizou-se uma Análise de Variância (ANOVA), empregando-se para tanto o programa computacional Statistica 7, verificando-se as variáveis significativas no ensaio. Ainda se utilizando do programa foram buscadas correlações entre a RST e com outros parâmetros avaliados, tais como a resistência de aderência, o coeficiente de permeabilidade e índice esclerométrico. Para tanto, baseou-se no manual do programa Statistica 7 elaborado por Calado e Montgomery (2003).

A avaliação qualitativa de coeficiente de regressão (r) quanto à intensidade pode assumir tanto valores positivos (+) como negativos (-), conforme ilustrado na Figura 12. A magnitude de $r$ indica quão próximos da "reta" estão os pontos individuais. Quando o r se aproxima de +1 ou de -1 indica pouca dispersão e uma correlação muito forte, positiva ou negativa. Quando o $r$ se aproxima de "zero" indica muita dispersão e uma ausência de relacionamento.

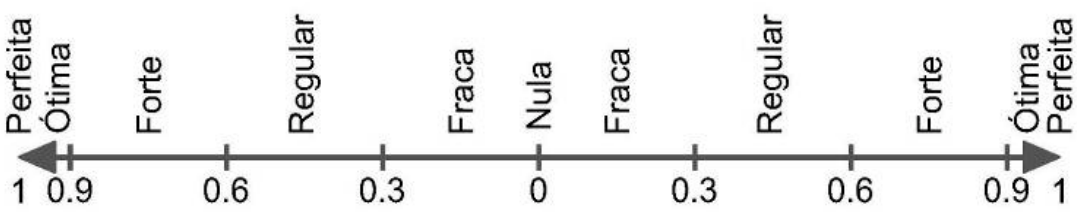

Figura 12. Avaliação qualitativa de coeficiente de regressão.

\section{RESULTADOS E DISCUSSÕES}

A Tabela 4 apresenta os resultados individuais de resistência superficial à tração obtidos em cada uma das condições testadas.

Tabela 4. Valores individuais de resistência superficial (em MPa).

\begin{tabular}{|c|c|c|c|c|c|c|c|}
\hline \multicolumn{1}{c}{ CPs } & A1 & A2 & A3 & A4 & B1 & B2 & B3 \\
\hline 1 & 0,14 & 0,44 & 0,26 & 0,55 & 0,24 & 0,09 & 0,08 \\
\hline 2 & 0,17 & 0,25 & 0,25 & 0,21 & 0,24 & 0,14 & 0,12 \\
\hline 3 & 0,14 & 0,31 & 0,17 & 0,16 & 0,11 & 0,20 & 0,24 \\
\hline 4 & 0,25 & 0,50 & 0,17 & 0,34 & 0,06 & 0,18 & 0,29 \\
\hline 5 & 0,28 & 0,50 & 0,18 & 0,47 & 0,24 & 0,22 & 0,20 \\
\hline 6 & 0,31 & 0,28 & 0,22 & 0,18 & 0,11 & 0,12 & 0,37 \\
\hline 7 & 0,31 & 0,52 & 0,17 & 0,27 & 0,28 & 0,32 & 0,20 \\
\hline 8 & 0,42 & 0,44 & 0,18 & 0,36 & 0,11 & 0,26 & 0,12 \\
\hline 9 & 0,55 & 0,50 & 0,10 & 0,17 & 0,17 & 0,26 & 0,13 \\
\hline
\end{tabular}

H. Carasek, O. Cascudo, M. S. J. dos Santos, N. Lemes 
Revista ALCONPAT, Volumen 1, Número 2, Mayo - Agosto 2011, Páginas 115 - 135

\begin{tabular}{|c|c|c|c|c|c|c|c|}
\hline 10 & 0,55 & 0,55 & 0,18 & 0,22 & 0,23 & 0,30 & 0,13 \\
\hline 11 & 0,25 & 0,42 & 0,30 & 0,42 & 0,17 & 0,27 & 0,36 \\
\hline 12 & 0,28 & 0,28 & 0,26 & 0,40 & 0,18 & 0,29 & 0,44 \\
\hline 13 & 0,55 & 0,44 & 0,15 & 0,21 & 0,23 & 0,29 & 0,23 \\
\hline 14 & 0,34 & 0,20 & 0,15 & 0,27 & 0,13 & 0,27 & 0,39 \\
\hline 15 & 0,76 & 0,44 & 0,07 & 0,23 & 0,18 & 0,30 & 0,43 \\
\hline 16 & 0,31 & 0,44 & 0,11 & 0,23 & 0,26 & 0,38 & 0,34 \\
\hline 17 & 0,39 & 0,31 & 0,16 & 0,51 & 0,17 & 0,23 & 0,23 \\
\hline 18 & 0,50 & 0,44 & 0,16 & 0,47 & 0,21 & 0,40 & 0,60 \\
\hline 19 & 0,39 & 0,36 & 0,28 & 0,27 & 0,11 & 0,34 & 0,33 \\
\hline 20 & 0,44 & 0,68 & 0,07 & 0,31 & 0,07 & 0,21 & 0,36 \\
\hline 21 & 0,42 & 0,42 & 0,21 & 0,22 & 0,35 & 0,32 & 0,27 \\
\hline 22 & 0,25 & 0,78 & 0,12 & 0,18 & 0,27 & 0,27 & 0,27 \\
\hline 23 & 0,55 & 0,20 & 0,18 & 0,29 & 0,14 & 0,46 & 0,33 \\
\hline 24 & 0,28 & 0,28 & 0,16 & 0,54 & 0,24 & 0,21 & 0,32 \\
\hline 25 & 0,34 & 0,20 & 0,19 & 0,38 & 0,29 & 0,38 & 0,24 \\
\hline 26 & 0,31 & 0,23 & 0,14 & 0,32 & 0,15 & 0,20 & 0,22 \\
\hline 27 & 0,25 & 0,25 & 0,12 & 0,32 & 0,20 & 0,23 & 0,15 \\
\hline 28 & - & 0,25 & 0,10 & 0,17 & 0,15 & 0,17 & 0,11 \\
\hline 29 & - & 0,42 & - & 0,16 & 0,13 & 0,20 & 0,12 \\
\hline 30 & - & 0,55 & - & 0,25 & - & - & - \\
\hline $\mathrm{N}^{0}$ de CPs & 27 & 30 & 28 & 30 & 29 & 29 & 29 \\
\hline Média (MPa) & 0,36 & 0,40 & 0,17 & 0,30 & 0,19 & 0,26 & 0,26 \\
\hline DP (MPa) & 0,15 & 0,14 & 0,06 & 0,12 & 0,07 & 0,09 & 0,12 \\
\hline CV (\%) & 42 & 35 & 35 & 40 & 37 & 35 & 46 \\
\hline
\end{tabular}

\subsection{Influência do operador no ensaio de Resistência Superficial à Tração}

Os ensaios foram realizados seguindo a sequiência cronológica de execução apresentada na Tabela 5, a influência do operador na variação dos resultados, bem como do ganho de experiência por parte dos operadores na redução do coeficiente de variação, pode ser observada na Figura 13.

Tabela 5. Seqüência de execução de ensaios.

\begin{tabular}{|c|c|c|c|}
\hline $\begin{array}{c}\text { Seqüiência de execução } \\
\text { dos ensaios }\end{array}$ & Código do Painel & Operador & $\begin{array}{c}\text { Coeficiente de Variação } \\
(\%)\end{array}$ \\
\hline 1 & A1 & $\alpha+\gamma$ & 42 \\
\hline 2 & A2 & $\alpha$ & 35 \\
\hline 3 & A3 & $\alpha+\beta$ & 35 \\
\hline 4 & B1 & $\alpha$ & 37 \\
\hline 5 & B2 & $\alpha$ & 35 \\
\hline 6 & B3 & $\beta+\alpha$ & 46 \\
\hline 7 & A4 & $\beta$ & 40 \\
\hline
\end{tabular}




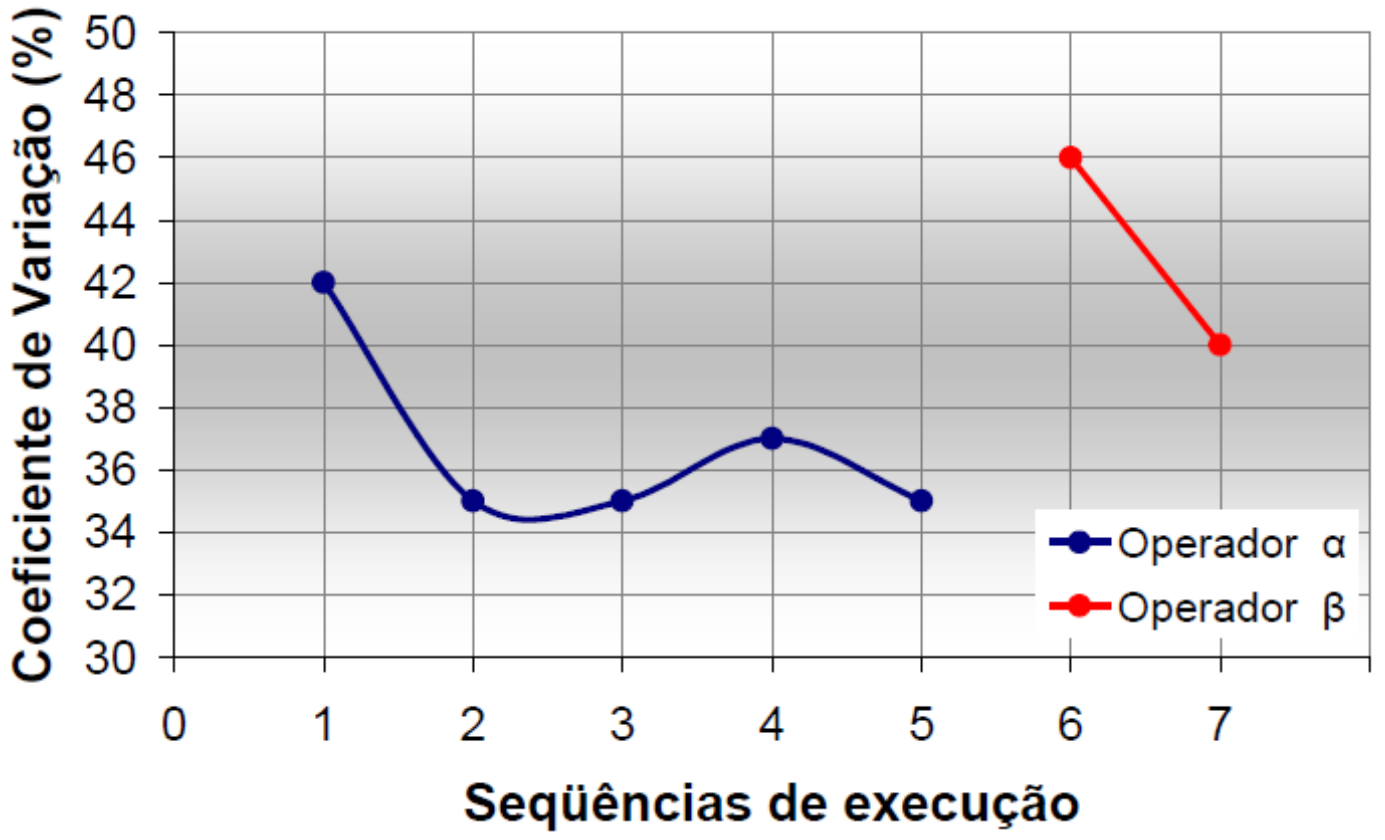

Figura 13. Coeficiente de variação dos resultados de resistência superficial em função da sequiência cronológica de execução, separados por operador.

Os resultados das seqüências 1 e 6 demonstram os coeficientes de variação obtidos na primeira execução do ensaio para cada um dos operadores $\alpha(\mathrm{e} \beta)$, os quais ainda $\mathrm{n}$ ão tinham experiência na realização do teste e, portanto, introduziram grande variação nos resultados. Após a primeira execução os coeficientes de variação obtiveram uma queda significativa, de $7 \%$ e $6 \%$, respectivamente para os operadores $\alpha$ e $\beta$, ficando mais estáveis, por volta de $36 \%$. Observa-se então a necessidade de treinamento da mão-de-obra que realizará o ensaio, visando à redução da variabilidade obtida.

Tabela 6. Valores finais adotados para cálculo.

\begin{tabular}{|c|c|c|c|}
\hline $\begin{array}{c}\text { Sequiência de execução } \\
\text { dos ensaios }\end{array}$ & Código do Painel & Operador & $\begin{array}{c}\text { Coeficiente de Variação } \\
(\%)\end{array}$ \\
\hline 2 & A2 & $\alpha$ & 35 \\
\hline 3 & A3 & $\alpha+\beta$ & 35 \\
\hline 4 & B1 & $\alpha$ & 37 \\
\hline 5 & B2 & $\alpha$ & 35 \\
\hline 7 & A4 & $\beta$ & 40 \\
\hline & & Média & 36 \\
\hline
\end{tabular}

Assim, para o cálculo do tamanho da amostra, conforme descrito no item 3.4, empregou-se, então, a média dos coeficientes de variação obtidos ( $\mathrm{CV}=36 \%$, conforme Tabela 6), excluindo-se a primeira execução de cada operador e adotando-se os valores já estabilizados devido à experiência dos operadores. 


\subsection{Tamanho da amostra para ensaio de Resistência Superficial à Tração}

Para um nível de confiança de $95 \%$, tem-se que $Z \alpha / 2=Z 0,025=1,96$ (valor tabelado da distribuição normal). Adotando-se o CV médio de $36 \%$ e aceitando um $\mathrm{ER}=20 \%$, tem-se o cálculo do tamanho da amostra apresentado na Tabela 7. Na Tabela 8 é mostrado o cálculo quando se adota o CV médio de $36 \%$ e se aceita um erro um pouco maior, de $25 \%$.

Tabela 7. Cálculo do tamanho da amostra para CV $36 \%$ e Erro $20 \%$.

\begin{tabular}{|c|c|c|c|c|c|c|c|}
\hline \multicolumn{2}{|c|}{} & \multicolumn{2}{c|}{$\begin{array}{c}\mathrm{n}=12,11 \text { graus } \\
\text { de liberdade }\end{array}$} & \multicolumn{2}{c|}{$\begin{array}{c}\mathrm{n}=16,15 \text { graus } \\
\text { de liberdade }\end{array}$} & $\begin{array}{c}\mathrm{n}=15,14 \text { graus de } \\
\text { liberdade }\end{array}$ \\
\hline $\mathrm{CV}$ & 36 & $\mathrm{CV}$ & 36 & $\mathrm{CV}$ & 36 & $\mathrm{CV}$ & 36 \\
\hline $\mathrm{ER}$ & 20 & $\mathrm{ER}$ & 20 & $\mathrm{ER}$ & 20 & $\mathrm{ER}$ & 20 \\
\hline $\mathrm{Z}_{0,025}$ & 1,960 & $\mathrm{Z}_{0,025}$ & 2,201 & $\mathrm{Z}_{0,025}$ & 2,131 & $\mathrm{Z}_{0,025}$ & 2,145 \\
\hline $\mathrm{n}$ & 12,45 & $\mathrm{n}$ & 15,70 & $\mathrm{n}$ & 14,71 & $\mathrm{n}$ & 14,91 \\
\hline $\mathrm{n} \sim$ & 12 & $\mathrm{n} \sim$ & 16 & $\mathrm{n} \sim$ & 15 & $\mathrm{n} \sim$ & 15 \\
\hline
\end{tabular}

No caso do erro admitido de $20 \%$ observou-se a convergência para um número igual a 15 corposde-prova.

Tabela 8. Cálculo do tamanho da amostra para CV $36 \%$ e Erro $25 \%$.

\begin{tabular}{|c|c|c|c|c|c|c|c|c|c|}
\hline \multicolumn{2}{|c|}{} & \multicolumn{2}{c}{$\begin{array}{c}\mathrm{n}=8,7 \text { graus } \\
\text { de liberdade }\end{array}$} & \multicolumn{2}{c|}{$\begin{array}{c}\mathrm{n}=12,11 \text { graus } \\
\text { de liberdade }\end{array}$} & \multicolumn{2}{c|}{$\begin{array}{c}\mathrm{n}=10,9 \text { graus } \\
\text { de liberdade }\end{array}$} & \multicolumn{2}{c|}{$\begin{array}{c}\mathrm{n}=11,10 \text { graus } \\
\text { de liberdade }\end{array}$} \\
\hline $\mathrm{CV}$ & 36 & $\mathrm{CV}$ & 36 & $\mathrm{CV}$ & 36 & $\mathrm{CV}$ & 36 & $\mathrm{CV}$ & 36 \\
\hline $\mathrm{ER}$ & 25 & $\mathrm{ER}$ & 25 & $\mathrm{ER}$ & 25 & $\mathrm{ER}$ & 25 & $\mathrm{ER}$ & 25 \\
\hline $\mathrm{Z}_{0,025}$ & 1,96 & $\mathrm{Z}_{0,025}$ & 2,365 & $\mathrm{Z}_{0,025}$ & 2,201 & $\mathrm{Z}_{0,025}$ & 2,262 & $\mathrm{Z}_{0,025}$ & 2,228 \\
\hline $\mathrm{n}$ & 7,97 & $\mathrm{n}$ & 11,60 & $\mathrm{n}$ & 10,05 & $\mathrm{n}$ & 10,61 & $\mathrm{n}$ & 10,29 \\
\hline $\mathrm{n} \sim$ & 8 & $\mathrm{n} \sim$ & 12 & $\mathrm{n} \sim$ & 10 & $\mathrm{n} \sim$ & 11 & $\mathrm{n} \sim$ & 10 \\
\hline
\end{tabular}

Para um erro de $25 \%$ ocorreu a convergência para uma amostragem igual a 10 corpos-de-prova. $\mathrm{O}$ tamanho de amostra inicialmente encontrado (15 CPs) é bastante elevado refletindo a alta variação obtida, típica de ensaios realizados em revestimentos de argamassa, principalmente quando estes são aplicados em condições de obra. A esse respeito, cabe destacar-se que são freqüentes coeficientes de variação no ensaio de resistência de aderência oscilantes entre $10 \%$ e $35 \%$ e em alguns casos esse coeficiente supera 50\% (Cincotto, Silva e Carasek, 1995; Carasek, 2007; Costa, 2007). Por outro lado, é importante ressaltar que, no enfoque de ciência dos materiais, está se falando de um material frágil (argamassa), o qual se caracteriza por apresentar uma alta dispersão dos resultados de ruptura. Uma alternativa para a diminuição do número de corpos-de-prova é a aceitação de um erro um pouco maior, mas ainda aceitável para experimentos em obra, de 25\% (NANNI; RIBEIRO, 1987) que reduziria o tamanho da amostra para 10 corpos-de-prova, mais viável de realização em obra..

\subsection{Análise de Variância (ANOVA) dos resultados globais RST}

A Tabela 9 apresenta os resultados da Análise de Variância (ANOVA) realizada visando verificar quais fatores estudados (apresentados na Tabela 3) exercem influência significativa nos resultados de resistência superficial do revestimento (apresentados na Tabela 4).

Tabela 9. Resultados da análise de variância (ANOVA) para a Resistência Superficial à Tração Avaliação em obra da resistência superficial de revestimentos de argamassa 
Revista ALCONPAT, Volumen 1, Número 2, Mayo - Agosto 2011, Páginas 115 - 135

\begin{tabular}{|c|c|c|c|c|c|c|}
\hline Fonte & SQ & GL & MQ & Fcal & Ftab & Resultado \\
\hline Obra & 0,2986 & 1 & 0,2986 & 21,5256 & 3,8826 & Significativo \\
\hline Local & 0,1134 & 1 & 0,1134 & 8,1747 & 3,8826 & Significativo \\
\hline Idade & 0,1760 & 1 & 0,1760 & 12,6916 & 3,8826 & Significativo \\
\hline Erro & 3,1626 & 228 & 0,0139 & & & \\
\hline
\end{tabular}

Onde: $\mathrm{SQ}=$ soma dos quadrados; $\mathrm{GL}=\mathrm{Grau}$ de liberdade; $\mathrm{MQ}=$ Média dos quadrados; $\mathrm{F}=$ parâmetro de Fischer para o teste de significância dos efeitos.

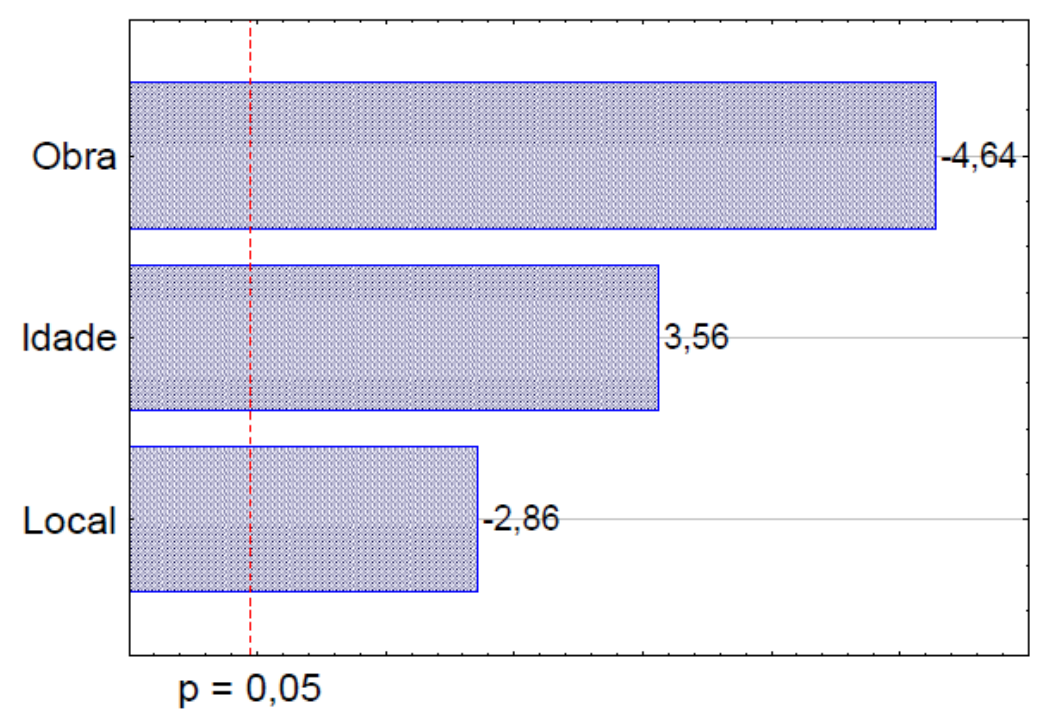

Figura 14. Diagrama de Pareto mostrando significância das variáveis da análise de variância (ANOVA) para a Resistência Superficial à Tração.

Na ANOVA realizada todos os fatores são significativos; observando-se o diagrama de Pareto (Figura 14) pode-se notar que a obra exerce uma maior influência, isso acontece devido à variação do traço da argamassa aplicada além da técnica de execução e do operário estarem englobados em cada obra das duas construtoras avaliadas. A idade é significativa, ocorrendo um aumento da resistência de 7 para 35 dias, explicado pela hidratação do cimento e da carbonatação da cal ao longo do tempo. A significância do local de execução do revestimento é explicada devido às influências das intempéries de maior intensidade encontradas na parede externa, entre elas insolação, ciclos de molhagem e secagem (chuva) e variação intensidade de CO2. 
Revista ALCONPAT, Volumen 1, Número 2, Mayo - Agosto 2011, Páginas 115 - 135

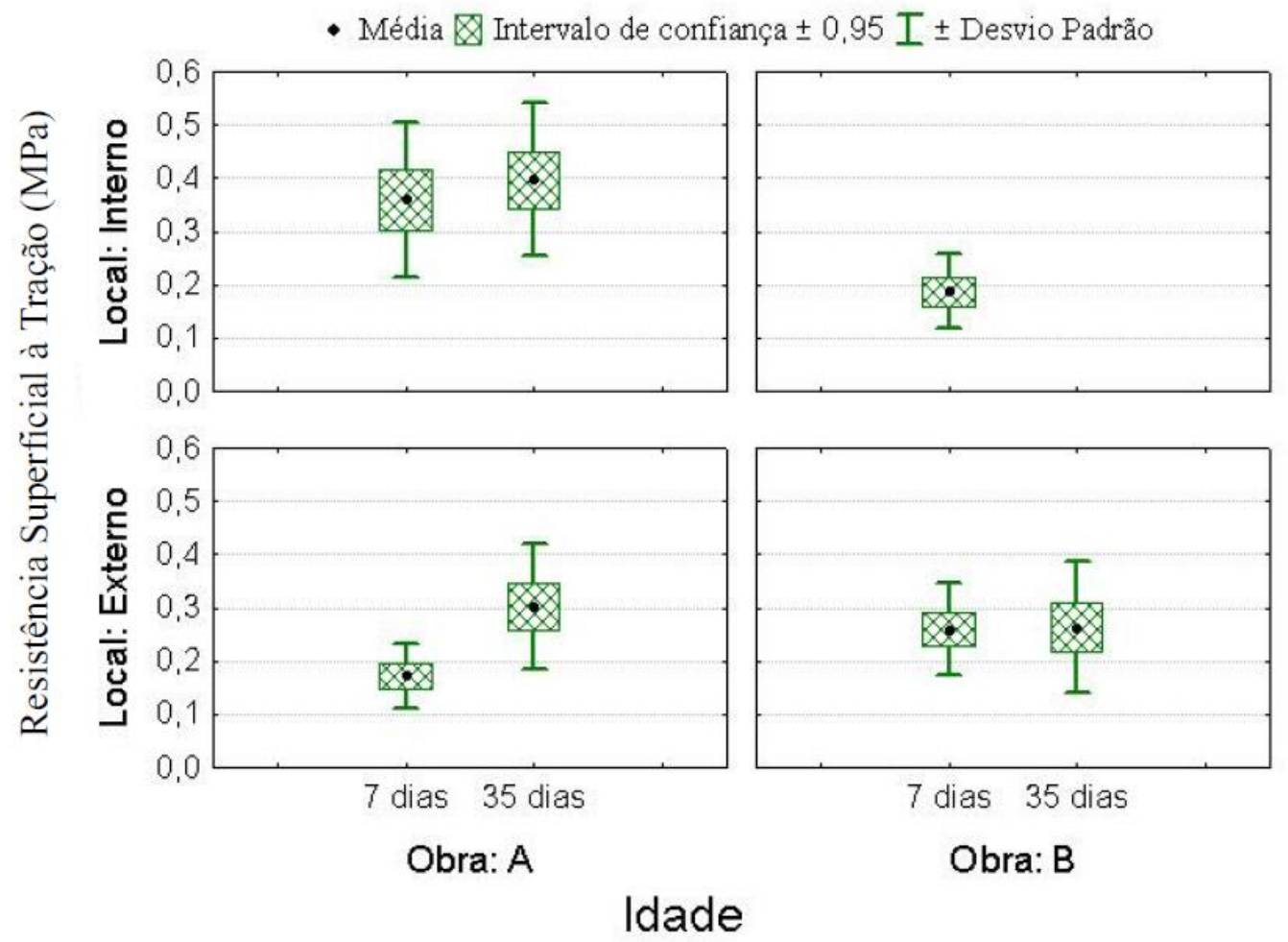

Figura 15. Valores médios globais da Resistência Superficial à Tração (em MPa) para todos os traços de argamassa estudados com seus intervalos de confiança de $95 \%$ e seus desvios padrões.

Na Figura 15 pode-se observar a evolução da resistência superficial à tração ao longo do tempo; todos os revestimentos estudados apresentaram um comportamento semelhante e tiveram um crescimento nos resultados dos 7 dias para os 35 dias de idade. $\mathrm{O}$ maior crescimento ocorreu na parede externa da Obra A. Isto pode ser explicado em função do traço da Obra A ser mais rico em cimento, o que lhe confere um maior ganho de resistência ao longo do tempo.

Para os ensaios realizados na parede interna da Obra A e na parede externa da Obra B, onde se aplicou chapisco sobre o substrato, foi possível observar resultados com valores de resistência superiores em relação aos ensaios realizados sem chapisco. Esta observação é interessante uma vez que o teste é realizado na superfície do revestimento. Isto confirma que a base e sua capacidade de sucção de água exercem influência até a superfície do revestimento e não só na interface substrato/argamassa, como já é bem conhecido pelos estudos de resistência de aderência de revestimentos. A influência da base na RST de revestimentos já havia sido constatada por Pereira, Carasek e Francinete Jr. (2005), quando foram notados resultados superiores de resistência dos revestimentos aplicados sobre blocos de concreto aos aplicados sobre blocos cerâmicos.

$\mathrm{Na}$ parede interna da obra B não houve realização do ensaio aos 35 dias devido a problemas de acesso ao local no dia de execução do ensaio. 


\subsection{Influência da ergonomia}

A Figura 16 apresenta um exemplo de gráfico obtido com as iso-tensões nos painéis de revestimento.

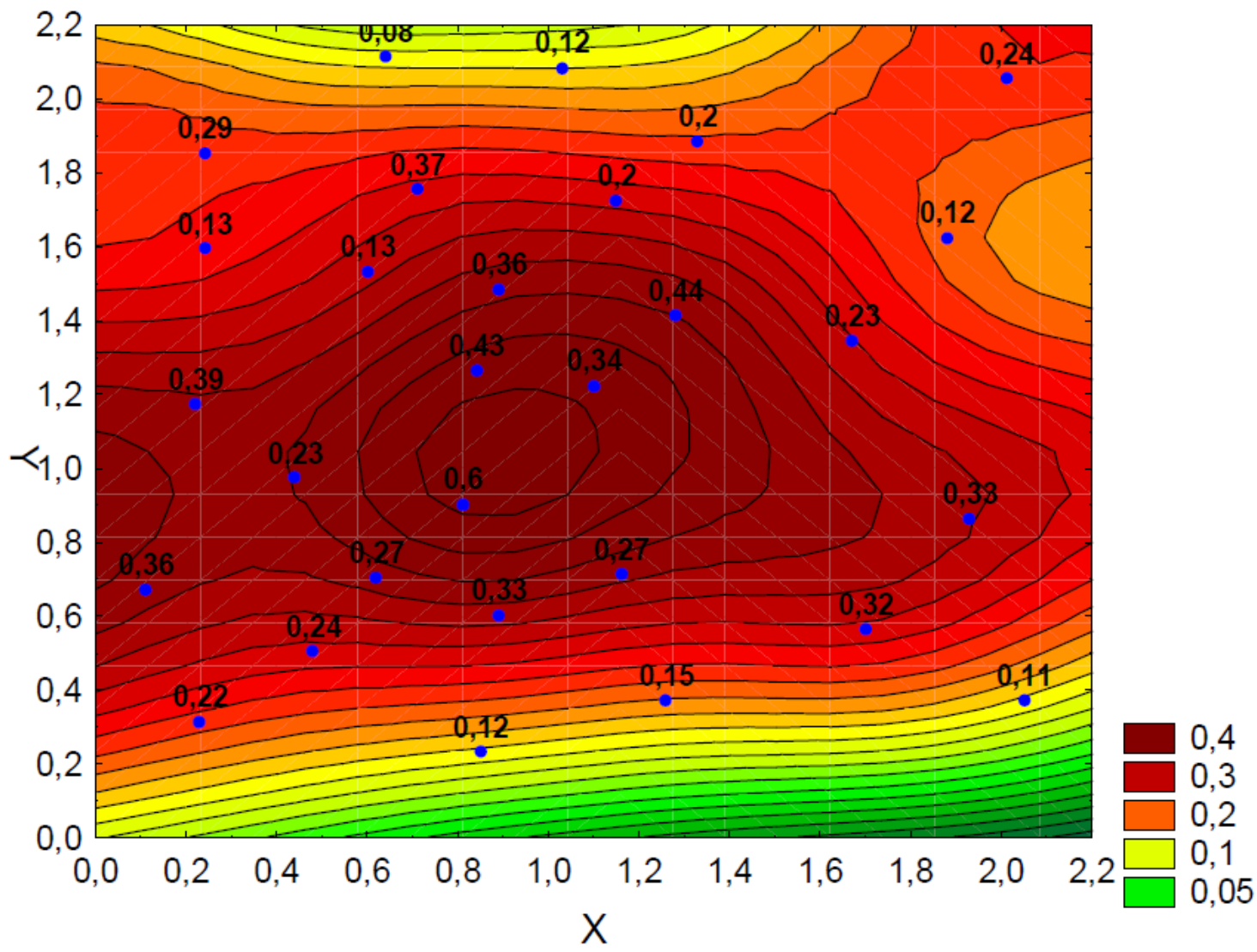

Figura 16. Curvas de iso-tensão (em MPa) do painel B3.

Nesta figura pode-se observar a influência da ergonomia nos resultados de resistência superficial, ou seja, a influência da posição do revestimento testado no painel (principalmente a altura) em relação às condições de aplicação da argamassa pelo pedreiro.

Para analisar a influência da ergonomia nos resultados de RST, o painel foi dividido em níveis de distribuição vertical e horizontal, mostrados na Tabela 10. As Figuras 17 e 18 mostram os resultados dos valores médios globais da resistência superficial em relação à posição na horizontal e na altura, respectivamente.

Tabela 10. Divisão dos painéis para a avaliação da ergonomia.

\begin{tabular}{|c|c|c|}
\hline Posição & Altura & Níveis \\
\hline Esquerda & Baixo & $0,75 \mathrm{~m} \geq X>0$ \\
\hline Centro & Médio & $1,50 \mathrm{~m} \geq X>0,75 \mathrm{~m}$ \\
\hline Direita & Alto & $X>1,50 \mathrm{~m}$ \\
\hline
\end{tabular}




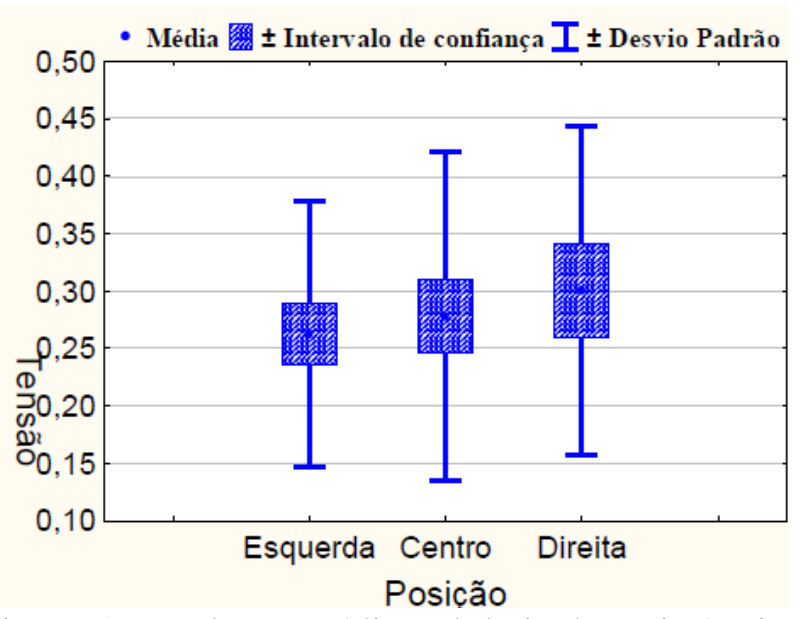

Figura 17. Valores médios globais da resistência superficial (em MPa) em relação à posição na horizontal.

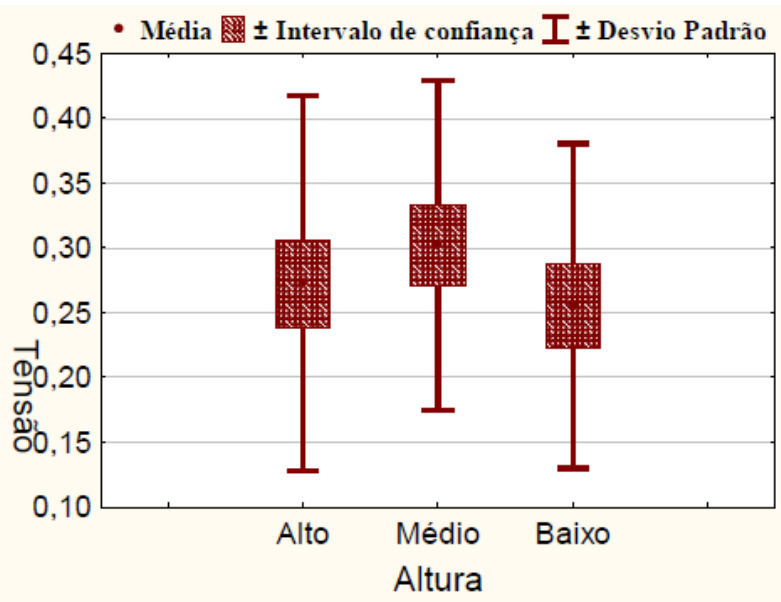

Figura 18. Valores médios globais da resistência superficial (em MPa) em relação à altura.

Cabe salientar-se que as regiões "alto" e "baixo" dos painéis, contém, respectivamente, encontros com a laje e com o piso, já nas laterais (posição horizontal), os painéis da obra B têm em sua lateral esquerda o encontro de paredes. Estas situações restringem os movimentos completos do operário na fase de execução, aplicação e acabamento, do revestimento de argamassa o que prejudica a resistência superficial. Com base nessa informação podem-se explicar as oscilações de resistência encontradas (Figuras 17 e 18); observa-se que nas regiões onde o movimento é restrito há uma redução no valor de tensão comparado com as regiões de livre movimentação. Por outro lado, as variações observadas com relação à altura, são explicadas também, e principalmente, pela maior energia de aplicação da argamassa (ao chapar), bem como a maior pressão ao sarrafear e desempenar o revestimento, conseqüência da posição mais adequada para a realização do trabalho pelo pedreiro.

\subsection{Correlações da RST com outros ensaios}

Nas tabelas a seguir são mostrados os resultados médios obtidos nos demais ensaios executados nos revestimentos de argamassa a fim de tentar estabelecer correlações com a RST.

a) Resistência de aderência à tração

A Tabela 11 apresenta os resultados médios de resistência de aderência à tração obtidos nos painéis testados e a Tabela 12 os percentuais das diferentes rupturas obtidas, anotadas de acordo com a Figura 19.

Tabela 11. Resultados médios obtidos no ensaio de aderência à tração.

\begin{tabular}{|c|c|c|c|c|c|c|c|}
\hline Painéis & $\mathbf{A 1}$ & $\mathbf{A 2}$ & $\mathbf{A 3}$ & $\mathbf{A 4}$ & $\mathbf{B 1}$ & $\mathbf{B 2}$ & $\mathbf{B 3}$ \\
\hline $\mathrm{N}^{\text {o }}$ de ensaios & 5 & 6 & 6 & 6 & 6 & 6 & 6 \\
\hline Tensão $(\mathrm{MPa})$ & 0,17 & 0,24 & 0,04 & 0,10 & 0,09 & 0,11 & 0,17 \\
\hline
\end{tabular}



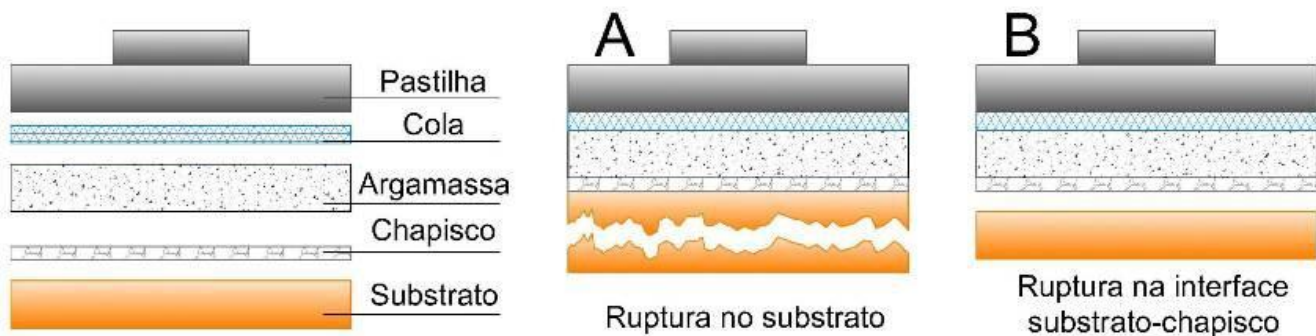

Ruptura no substrato

Ruptura na interface substrato-chapisco

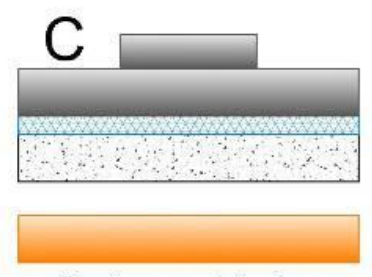

Ruptura na interface substrato-argamassa

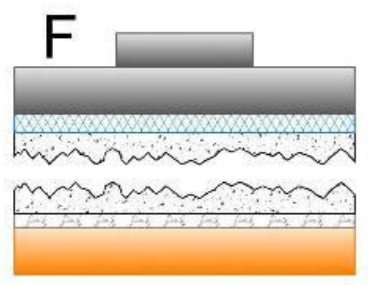

Ruptura na argamassa

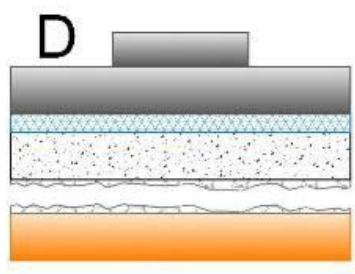

Ruptura no chapisco

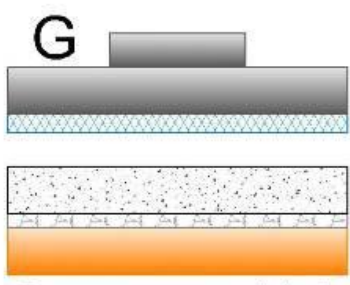

Ruptura na superficie da argamassa

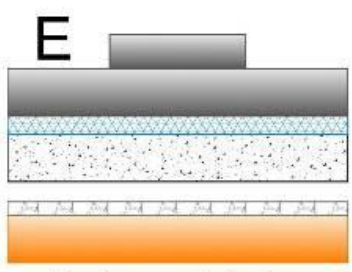

Ruptura na interface chapisco-argamassa

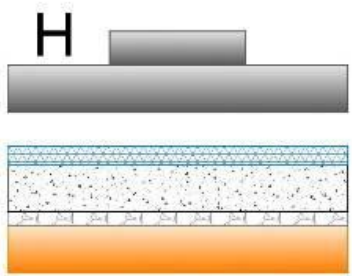

Ruptura na interface cola-pastilha

Figura 19. Formas de ruptura no ensaio de determinação da resistência de aderência à tração de revestimento

Tabela 12. Percentuais dos diferentes tipos de ruptura obtidos nos ensaios de resistência de aderência.

\begin{tabular}{|c|c|c|c|c|c|c|c|c|}
\hline Forma & Local de Ruptura & A1 & A2 & A3 & A4 & B1 & B2 & B3 \\
\hline A & substrato & - & - & - & - & - & - & - \\
\hline B & substrato / chapisco & - & $33 \%$ & - & - & - & - & - \\
\hline C & substrato / argamassa & - & - & $100 \%$ & $100 \%$ & $84 \%$ & - & - \\
\hline D & chapisco & - & $17 \%$ & - & - & - & - & - \\
\hline E & chapisco / argamassa & $70 \%$ & - & - & - & - & - & - \\
\hline F & argamassa & $30 \%$ & $50 \%$ & - & - & $16 \%$ & $100 \%$ & $100 \%$ \\
\hline G & superficial & - & - & - & - & - & - & - \\
\hline H & cola & - & - & - & - & - & - & - \\
\hline
\end{tabular}

A Figura 20 apresenta a correlação obtida entre os resultados médios de resistência de superficial de resistência de aderência à tração. 
Revista ALCONPAT, Volumen 1, Número 2, Mayo - Agosto 2011, Páginas 115 - 135

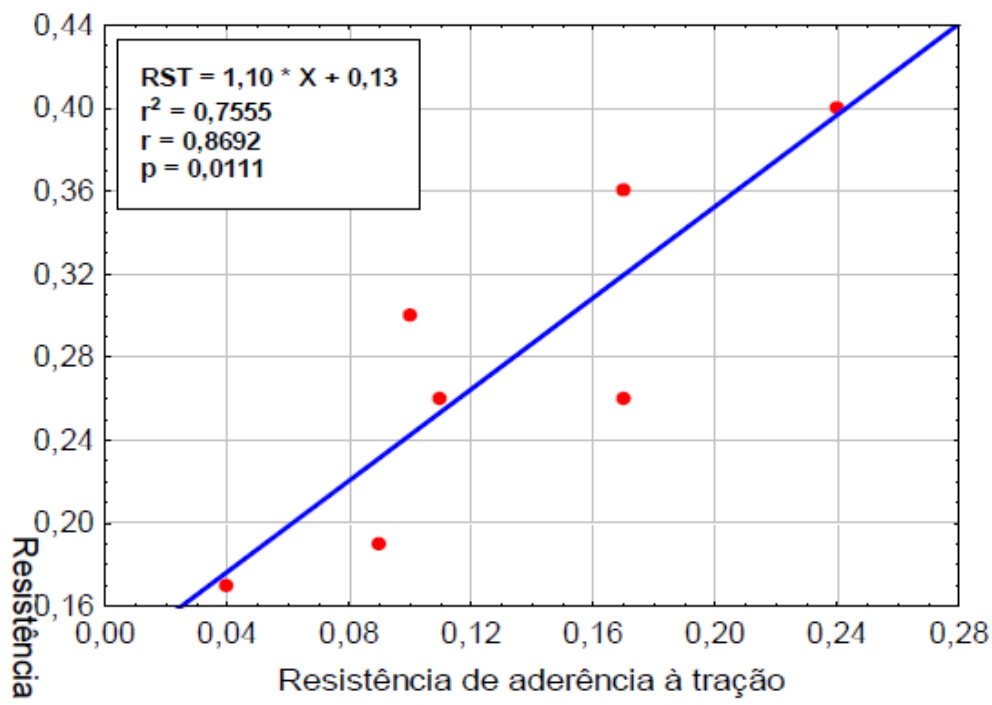

Figura 20. Correlação entre RST e resistência de aderência dos revestimentos, em MPa.

b) Permeabilidade/absorção de água pelo método do cachimbo

A partir dos gráficos de absorção de água ao longo do tempo, obtidos no método do cachimbo, foram calculados os coeficientes de permeabilidade para cada uma das situações testadas, utilizando a metodologia proposta por Dias (2003). Os valores médios dos coeficientes de permeabilidade estão apresentados na Tabela 13 e a Figura 21 apresenta a correlação obtida ente a RST e permeabilidade dos revestimentos.

Tabela 13. Resultados obtidos no ensaio de permeabilidade/absorção de água.

\begin{tabular}{|l|c|c|c|c|c|c|}
\hline Painéis & A & A & A & B & B & B \\
\hline $\mathbf{N}^{\mathbf{0}}$ de ensaios & 3 & 3 & 3 & 2 & 2 & 2 \\
\hline $\begin{array}{l}\text { Coeficiente de Permeabilidade } \boldsymbol{A}_{2-} \\
8(\boldsymbol{m l} \boldsymbol{x} \text { min })\end{array}$ & 7,30 & 8,45 & 7,35 & 8,95 & 9,10 & 9,30 \\
\hline
\end{tabular}

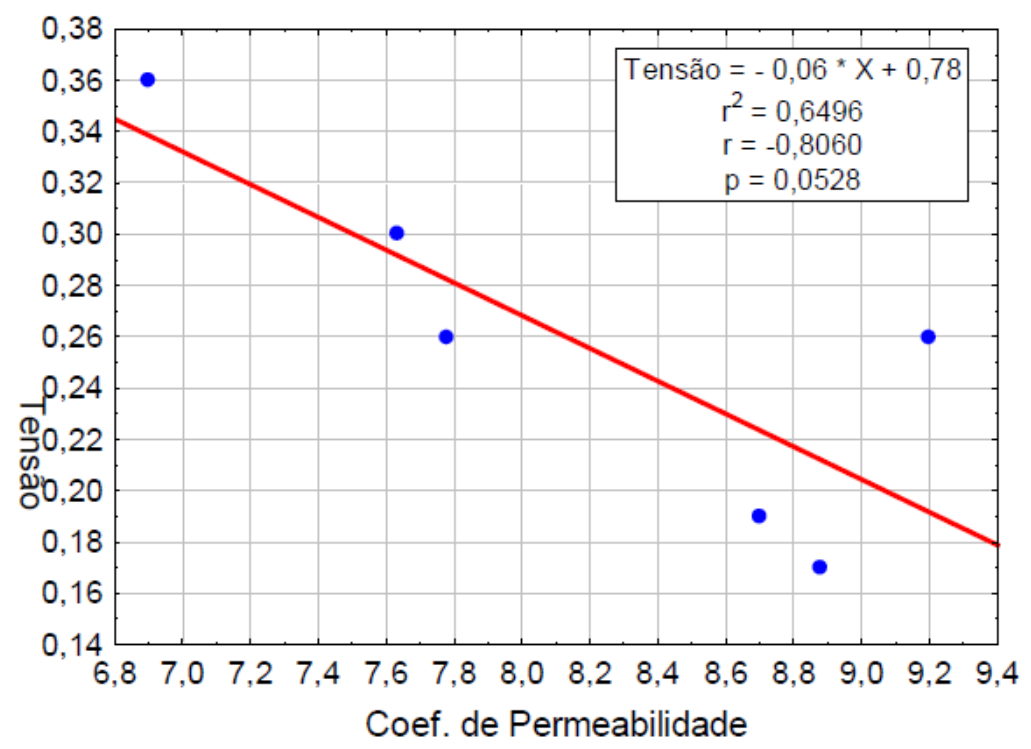

Figura 21. Correlação entre RST (MPa) e coeficiente de permeabilidade (mL. Min) dos revestimentos. 
c) Esclerometria de pêndulo

A Tabela 14 apresenta os resultados médios do índice esclerométrico obtidos nas diferentes situações testadas.

Tabela 14. Índice esclerométrico.

\begin{tabular}{|c|c|c|c|c|}
\hline Painéis & A4 & B1 & B2 & B3 \\
\hline $\mathrm{N}^{\text {o }}$ de ensaios & 10 & 10 & 10 & 10 \\
\hline Valor Médio & 77,9 & 61,2 & 60,3 & 70,9 \\
\hline
\end{tabular}

A Figura 22, a seguir, ilustra a correlação obtida entre a resistência superficial e o índice esclerométrico.

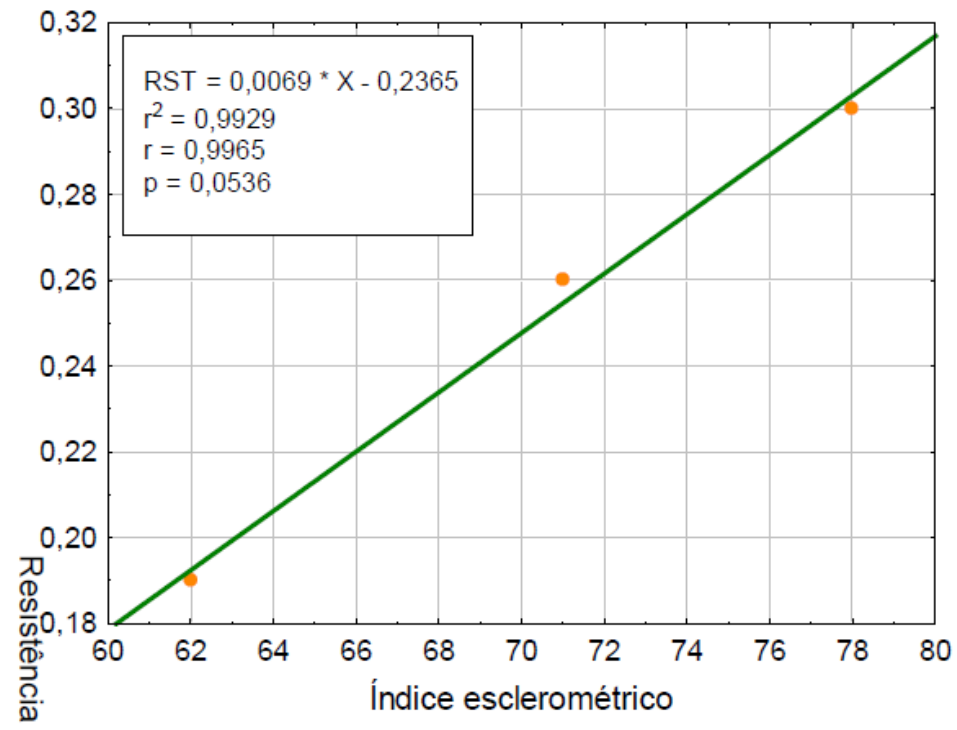

Figura 22. Correlação entre RST (MPa) e índice esclerométrico dos revestimentos.

Nas três figuras anteriores, pode-se observar que a resistência superficial à tração apresenta boa correlação com os demais resultados de ensaios. Os valores de r obtidos, confrontados com os parâmetros da Figura 12, foram: 20);

RST x resistência de aderência - valor de $\mathrm{r}$ igual a 0,87, que indica uma correlação forte (Figura

RST x coeficiente de permeabilidade - valor de $\mathrm{r}$ igual a 0,81 , que indica uma correlação forte (Figura 21);

RST x índice esclerométrico - valor de r igual a 0,99, que indica uma correlação ótima (Figura 22).

Estes resultados contribuem para a comprovação da eficácia do método de ensaio de determinação da resistência superficial à tração de revestimentos, pois este sendo um ensaio ainda não normalizado gera resultados realmente significativos em relação a outros procedimentos já normalizados. Cabe destacar-se a ótima correlação obtida entre a RST e o índice esclerométrico; resultado este semelhante ao encontrado por Passos et al. (2008).

\section{CONCLUSÕES}

A seguir estão traçadas as principais conclusões obtidas neste trabalho:

Para a realização do ensaio de determinação da resistência superficial de revestimentos de argamassa, assim como para todos os ensaios, é necessário o correto treinamento do operador. Um 
resultado interessante deste trabalho foi a redução do coeficiente de variação obtido no ensaio à medida que o operador ganhou experiência, sendo esta redução de até 7\%. No caso em questão, após bem instruído quanto aos procedimentos de execução do ensaio e a realização de cerca de 30 testes, o operador estava apto a realizar o ensaio, sem introduzir variação excessiva aos resultados devido ao procedimento.

O tamanho de amostra necessário para a realização do ensaio de determinação da resistência superficial de revestimentos de argamassa com adequada confiabilidade é de 15 corpos-de-prova, quando se admite um erro de $20 \%$. No caso de se tolerar um erro um pouco maior, de $25 \%$, encontrou-se como tamanho da amostra 10 corpos-de-prova. Estes tamanhos de amostras foram calculados com base em um coeficiente de variação (CV) de 36\%, obtido em média nos experimentos realizados. Apesar de alto este CV, ele é compatível com os coeficientes obtidos no ensaio de resistência de aderência à tração que variam geralmente entre $10 \%$ e $35 \%$ e, em alguns casos, chegam a superar 50\%. Estes ensaios preliminares mostram a necessidade de realização de novas pesquisas visando ajustes no método e identificação das principais fontes de variação, com o objetivo de redução do número de corpos-de-prova necessário, mas com a confiabilidade adequada. Constatou-se que fatores como obra (onde este engloba variações do traço da argamassa de revestimento e das técnicas de execução), idade do revestimento ( 7 e 35 dias) e ação de intempéries influenciam diretamente na resistência superficial dos revestimentos de argamassa. $\mathrm{O}$ prosseguimento desta pesquisa deve isolar e controlar em laboratório estas variáveis, visando entender e comprovar seus níveis de significância.

Ficou comprovado o efeito da ergonomia na RST dos revestimentos. Quanto maior a facilidade de aplicação da argamassa e realização do acabamento da superfície do revestimento, maiores são os valores obtidos de resistência superficial. Observou-se que nas regiões onde o movimento do pedreiro é restrito (devido à obstrução de elementos como outras paredes, pilares e lajes ou pisos) há uma redução no valor de tensão comparado com as regiões de livre movimentação. Por outro lado, as variações observadas com relação à altura, são explicadas também, e principalmente, pela maior energia de aplicação da argamassa (ao chapar), bem como a maior pressão ao sarrafear e desempenar o revestimento, conseqüência da posição mais adequada para a realização do trabalho pelo pedreiro.

Nos três casos testados, foram obtidas boas correlações entre a resistência superficial à tração e os demais ensaios realizados. No caso das correlações com a resistência de aderência $(r=0,87)$ e com o coeficiente de permeabilidade $(\mathrm{r}=0,81)$ obtiveram-se correlações fortes. Já para o índice esclerométrico o coeficiente de regressão encontrado foi próximo a 1,0, indicando uma correlação ótima ou perfeita. Estes resultados contribuem para a comprovação da eficácia do método de ensaio de determinação da resistência superficial à tração de revestimentos, pois este sendo um ensaio ainda não normalizado gera resultados realmente significativos em relação a outros procedimentos já consagrados e/ou normalizados.

Assim, o método de RST é proposto para, de forma direta, analisar o estado da superfície de revestimentos que receberão acabamentos, como peças cerâmicas ou pintura. Este método é uma alternativa viável para o controle de revestimentos de argamassa, visando à redução de falhas que futuramente podem provocar acidentes inclusive com riscos à vida humana. Vários casos de descolamento de peças cerâmicas têm sido relatados em todos os países; assim o controle da resistência superficial ganha maior importância à medida que a prática construtiva dá mostras de que se caminha para a concepção de edifícios cada vez mais altos, muitas vezes com estruturas mais esbeltas e deformáveis do que as construídas no passado. 
Revista ALCONPAT, Volumen 1, Número 2, Mayo - Agosto 2011, Páginas 115 - 135

\section{AGRADECIMENTOS}

À CAPES - Coordenação de Aperfeiçoamento de Pessoal de Nível Superior - Brasil e ao CNPq Conselho Nacional de Desenvolvimento Científico e Tecnológico - Brasil, pelo apoio financeiro através de bolsas e auxílio à pesquisa.

\section{REFERÊNCIAS BIBLIOGRÁFICAS}

Associação Brasileira de Normas Técnicas - ABNT (1995) NBR 13528 - Revestimento de paredes e tetos de argamassas inorgânicas - Determinação da resistência de aderência à tração. Rio de Janeiro.

Calado, V.; Montgomery, D. C. (2003) Planejamento de experimentos usando o Statistica. Rio de Janeiro - RJ. E-papers serviços editoriais, 260 p.

Carasek, H. (2007) "Argamassas”, In: Isaia, G.C. (Ed.) Materiais de Construção Civil. São Paulo: Ibracon, cap.26, v.2, p.863-904.

Centre Scientifique et Technique de la Construccion - CSTC (1982). Hidrofuges de surface: choix et mise en oeuvre. Bruxelles, 24 p. (Note D'information Technique - NIT n. 140) Cincotto, M. A.; Silva, M. A. C; Carasek, H. (1995) Argamassas de revestimento: características, propriedades $e$ métodos de ensaio. São Paulo: Instituto de Pesquisas Tecnológicas (Publicação IPT 2378), 118 p. Boletim Técnico 68 IPT.

Costa, E. (2007) Investigação do método de ensaio de determinação da resistência de aderência de revestimentos de argamassa. Dissertação (Mestrado) - Curso de Mestrado em Engenharia Civil, Universidade Federal de Goiás, Goiânia, 2007. 205p.

Dias, L. de A. (2003) Avaliação da permeabilidade e da absorção de água de revestimentos de argamassa. Dissertação (Mestrado) - Curso de Mestrado em Engenharia Civil, Universidade Federal de Goiás, Goiânia, 2003. 190p.

European Standards - EN 1015-12 (2000) Methods of test for mortar for masonry - part 12: determination of adhesion of hardened rendering and plastering mortars on substrates.

Nanni, L. F.; Ribeiro J. L. (1987) Planejamento e avaliação de experimentos. Apostila do Curso de pós-graduação em engenharia civil - UFRGS, Porto Alegre - RS.

National Center for Preservation Technology and Training. (1999) Nondestructive Method for Hardness Evaluation of Mortars. US Department of the Interior National Park Service, Publication No. 1999-02.

Passos, J. S.; Cândido, W.F.; Mendes, M. V.; Araújo, A. M.; Carasek, H. (2008) Fissuração de argamassas de revestimento devido à retração plástica. 12p. ENTAC 2008. - XII Encontro Nacional de Tecnologia do Ambiente Construído.

Pereira, P.C. (2000) Influência da cura no desempenho de revestimento produzidos com argamassas inorgânicas. Goiânia-GO, Dissertação (Mestrado) - Escola de Engenharia Civil, Universidade Federal de Goiás.

Pereira, P.C. Carasek, H. Francinete Jr., P. (2005) Influência da cura no desempenho de revestimentos de argamassas inorgânicas. In. SIMPÓSIO BRASILEIRO DE TECNOLOGIA DAS ARGAMASSAS, $6^{\circ}$, Florianópolis, p.477-486.

Selmo, S. M. S. (1989) Dosagem de argamassas de cimento e cal para revestimento externo de fachada de edifícios. São Paulo: USP, 187p. Dissertação (Mestrado em Engenharia de Construção Civil), Universidade de São Paulo, São Paulo.

Temoche-Esquivel, J.F. Ribeiro, F.A. Barros, M.M.B.; Sabbatini, F.H. (2005) Avaliação da influência das condições de execução do emboço na resistência de aderência do revestimento cerâmico externo. In. SIMPÓSIO BRASILEIRO DE TECNOLOGIA DAS ARGAMASSAS, $6^{\circ}$, Florianópolis, p. 454-465.

H. Carasek, O. Cascudo, M. S. J. dos Santos, N. Lemes 